phasize the acoustic isolation of ear from skull and jaws and ear from ear. The part played by the albuminous foam formed by nitrogen in an oil-mucus emulsion was discussed, and it was shown how this foam can remain persistent even during a prolonged dive.

Finally the modifications of the middle ear ossicles were described with reference to the requirement for successful matching of the cetacean ear to water- borne sound. They were illustrated by a working model.

A series of anatomical exhibits was shown to illustrate the specialization in the topographic relationship between ear and skull, especially the arrangement of air sinuses in the various cetaceans.

The contributions to the symposium will be published in full in the Proceedings of the Royal Society.

O. LoWENSTEIN

\title{
THE INDIAN ASSOCIATION FOR THE CULTIVATION OF SCIENCE
}

\begin{abstract}
7 HE annual report for 1957-58 of the Indian Association for the Cultivation of Science*, which includes lists of papers published during the year under their departmental headings, records further work on the thermal diffusion and inter-diffusion of gases. An apparatus has been designed for measuring the thermal conductivity of diffusing gases and a new apparatus constructed for purifying high-pressure cornmercial hydrogen. The dimensions of the unit cell of naphthazarin have been re-determined by X-ray methods and further work on the molecular structure of this crystal is in progress. The work of the Department of Magnetism was reorganized and the study of paramagnetic anisotropy of dihalides of copper(II), the paramagnetic behaviour of fluosilicates and chlorostannates of copper(II) and meas. urement of the principal susceptibilities of paramagnetic crystals down to liquid-hydrogen temperatures has been undertaken, as well as the study of paramagnetic crystals both by the paramagnetic electron resonance and the proton resonance method. The anisotropy of many nickel(II) salts of similar constitution was studied to ascertain the effect of long-range crystalline fields in these salts, and work on paramagnetic alums of titanium(III), vanadium(III) and chromium(III) was completed.

In the Opties Department the Raman spectra of o-chlorophenol in different solvents, of $\alpha$ - and $\gamma$-picoline and their solutions in alcohol in liquid and solid state, and of ethylbenzene, chlorobenzene and bromobenzene in the frozen state at $-180^{\circ} \mathrm{C}$. have been determined and the ultra-violet absorption spectra of many aromatic compounds studied in the vapour, liquid and solid states, as well as those of

* Indian Association for the Cultivation of Science. Annual Report for 1957-59. Pp. 52. (Jadavpur, Calcutta : Indian Association for the Cultivation of Science, 1959.)
\end{abstract}

frozen 0.2 per cent and 25 per cent solutions of the dichlorobenzenes in iso-butyl alcohol at $-180^{\circ} \mathrm{C}$. and the Debye-Scherrer patterns due to frozen toluene, chlorobenzene and bromobenzene and to diphenyl at $32^{\circ} \mathrm{C}$. and at $-180^{\circ} \mathrm{C}$. The Department of Theoretical Physics was concerned mainly with the spin of an electron from five-dimensional wave equations, the influence of constant electric and magnetic fields on the spin of the particle, electronic energy bonds in lattices and some generalizations in relativistic cosmology.

In the Department of Physical Chemistry, investigations in high polymer chemistry related to the kinetics and chain transfer behaviour of methyl isopropenyl ketone, the aqueous polymerization of vinyl monomers in redox systems, the thermodynamic properties of binary mixtures, the determination of absolute values of the rate constants in polymerization and the preparation and properties of soil conditions of the krillium type. In general and analytical chemistry, work is being carried out on the mutual solubilization of oils and water, the decomposition of peroxides in different solvents and the velocity of ultrasonic waves in solutions and liquids. An apparatus has been assembled for determining the mutual solubilities of organic compounds in situ. The Department of Organic Chemistry continued its investigations on sesquiterpenoids, diterpenoids, triterpenoids and steroids, and in the Department of Inorganic Chemistry attention was concentrated on the study of co-ordination complexes and their applications in analytical ehemistry. It has been shown that 3- and 5-oximinomethylsalicylic acids and 3- and 5-aldehydosalicylic acids can be used for estimating thorium and its separation from the cerite earths.

\section{THE EAST AFRICAN INDUSTRIAL RESEARCH ORGANIZATION REPORT FOR 1957-58}

\begin{abstract}
THE annual report for 1957-58 of the East African Industrial Research Organization* records the official opening of the new headquarters of the Organization in Nairobi on February 14, 1958, and spectacular results from a close collaborative study by the Fuel Advisory Service with the Research and Economy Section of the Chief Mechanical Engineer's Department of the East African Railways and Harbours, notably in the design of a special burner for lighting up locornotive boilers and in increasing the power developed by locomotive engines

* East Africa High Commission. East African Industrial Research Organization Annual Report, 1957-1958. Pp. iit18. (Nairobi Government Printer, 1958.) Sh. 2.
\end{abstract}

in service, using a Giesil ejector. Advice was also given on the utilization of wood waste, and fuel economies of 5-20 per cent were demonstrated in some thirty factories. An oil-fired incinerator was designed for the new swine fever research centre at Mugaga and a similar but larger one for the new Welleome Foot-and-Mouth Disease Centre.

The Department of Fuel Technology and Chemical Engineering has also examined the use of solar driers and the dust-proofing of motor cars. Extensive work on the mechanical drying of Arabicz coffee has shown that damage is reduced by pre-drying and increased by increasing the final drying temperatures, and that, daylight has a marked effect on the liquoring quality 